\title{
Dermoscopy Features of Cutaneous Warts
}

\section{Mus'ab Al Rudaisat (D) Hao Cheng}

Department of Dermatology and Venereology, Sir Run Run Shaw Hospital, School of Medicine, Zhejiang University, Hangzhou City, People's Republic of China
Correspondence: Hao Cheng Tel +8613588706943

Email chenghaol@zju.edu.cn
Background: Cutaneous warts are benign epithelial skin lesions, caused by human papilloma virus (HPV). These warts can affect any part of the body, and the clinical presentation of cutaneous warts is highly variable, making it difficult to diagnose. Dermoscopy is a relatively new, non-invasive, diagnostic tool, which can assist in the identification of different types of skin lesions.

Purpose: The purpose of this research article is to determine the effectiveness of dermoscopy in discerning the most common characteristics of cutaneous warts, in order to provide sufficient information on characteristic features of cutaneous warts, which may aid in differentiating cutaneous warts from other similar skin lesions.

Patients and Methods: A total of 104 patients diagnosed with warts were included in our study. Each individual case had one of the four different types of warts: common warts (26 cases), palmer warts (27 cases), plantar warts (25 cases), flat warts (26 cases).

Results: In this study, we found that a percentage of cutaneous warts appear clinically nonclassical, overlapping with other lesions. A 42\% (11 cases) of common warts were clinically nonclassical, and all of these cases presented with papillomatous growth. Other presentations were dotted, linear vessels, hairpin-like vessels and bleeding spots. All palmar wart cases were classical, while $8 \%$ ( 2 cases) of plantar warts were clinically nonclassical. The dermoscopic presentations were papillomatous growth, bleeding spots, dotted and linear vessels, structureless yellowish-gray appearance. Flat wart consisted of $11.5 \%$ (3 cases) with nonclassical clinical presentation. The dermoscopic presentation includes dotted and linear vessels, bleeding spots. Red, whitish (pale) and red-gray backgrounds.

Conclusion: Dermoscopy can improve the accuracy of diagnosing different types of clinically nonclassical cutaneous warts, as well as help in distinguishing them from other similar skin lesions.

Keywords: cutaneous warts, dermoscopy, diagnostic criteria, human papilloma virus, lowrisk HPV, HPV

\section{Introduction}

Cutaneous warts are benign epithelial lesions, caused by the human papilloma virus (HPV). They are generally asymptomatic, but in some cases, they have been known to cause to cause psychological impact or physical discomfort in patients, including cosmetic problems or even pain. Especially in the case of palmar and plantar warts. ${ }^{1,2}$

HPV can cause or malignant lesions, but cutaneous warts are benign, nonprecancerous lesions caused by low risk-HPV (LR-HPV). ${ }^{3}$ Of over $200 \mathrm{HPV}$ genotypes that have thus far been identified, at least 15 different subtypes have been associated with cutaneous warts. ${ }^{2,4}$

The general prevalence of viral cutaneous warts is around $7-12 \%$. The most prevalent genotypes of LR-HPV that cause cutaneous warts are HPV1/2/3/4/10/27/ 57 , and from these genotypes $1,2,4,27,57$ cause common warts, ${ }^{5,6}$ which present 
as papillomatous hyperkeratotic dome-shaped papule. Palmoplantar warts can be caused by genotypes 1 and 2 , and present as firm papule on palm and sole. On the other hand, plane warts are usually caused by genotypes 3 and 10 , clinically appearing as slightly elevated brown to beige colored papules, between 1 and $5 \mathrm{~mm}^{4}$

Dermoscopy is a relatively new diagnostic method. ${ }^{7}$ It is non-invasive and helps to identify different types of skin lesions, such as cancer and dermatitis. ${ }^{8,9}$

It is helpful in avoiding unnecessary biopsy, finding tumor margins, and identifying different characteristics of different lesions, including pigmentation, vessels, and scale. $^{10-13}$

Dermoscopy has provided an indispensable advantage for doctors in the diagnosis of skin lesions. ${ }^{14-17}$ There are several simplified Dermoscopy algorithms available designed to help doctors and even non-specialists master Dermoscopy. ${ }^{18-20}$

Dermoscopy could definitely help to improve the accuracy of diagnosis, but good training is required in order to make it a beneficial tool. ${ }^{21-26}$

Some studies have shown that after only a short amount of training Dermoscopy was able to help increase the accuracy of diagnosis, and improve the sensitivity of diagnosis without decreasing the specificity, especially when obtained by experts. ${ }^{10,27-29}$

Diagnosing warts can be challenging sometimes, as it could mimic many skin lesions like seborrheic keratosis (SK), calluses, corns, acne, and folliculitis. On the other hand, these lesions can also mimic warts.

Dermoscopy is not meant to be a substitute for other diagnostic method, but rather as an aid in differentiating warts from other similar skin lesions. It is an undeniable tool for the diagnosis of different cutaneous warts. The goal of this research is to observe cutaneous warts under the Dermoscope for the purpose or finding common and uncommon Dermoscopic characteristics in order to provide enough information, which may assist Dermatologists and GPs when diagnosing cutaneous warts, especially when differentiating between warts and other similar skin lesions.

\section{Materials and Methods}

Data of patients who had cutaneous warts on different parts of the body (except genital area) was retrospectively collected, from the outpatient department of Sir Run Run Shaw Hospital (SRRH), between October 1st, 2019 and April 20th, 2020.
Table I Clinical and Dermoscopic Observations of Classical and Nonclassical Cutaneous Warts

\begin{tabular}{|c|c|c|c|}
\hline \multicolumn{4}{|c|}{ Patients Characteristics } \\
\hline & \multicolumn{2}{|l|}{ Gender } & \multirow{2}{*}{$\begin{array}{c}\text { Mean Age } \\
\text { (Years) }\end{array}$} \\
\hline & Male & Female & \\
\hline Common wart & 13 & 13 & $51.3($ *sd 19.3) \\
\hline Palmer wart & 17 & 10 & 34.1 (*sdII.3) \\
\hline Plantar wart & 18 & 7 & $29.4(* s d 5.7)$ \\
\hline Flat wart & 11 & 15 & 26.9 (*sd 4.2) \\
\hline Total & 59 & 45 & $36(*$ sd I5.3) \\
\hline $\begin{array}{l}\text { Dermoscopic } \\
\text { features }\end{array}$ & \multicolumn{3}{|c|}{ Number (\%) } \\
\hline \multicolumn{4}{|l|}{ Common wart } \\
\hline & Papillomatous & $\begin{array}{c}26 \\
(100 \%)\end{array}$ & \\
\hline & $\begin{array}{l}\text { Frogspawn } \\
\text { appearance }\end{array}$ & $\begin{array}{c}11 \\
(42.3 \%)\end{array}$ & \\
\hline & Finger-like projections & 9 (34.6\%) & \\
\hline & Dotted vessels & $\begin{array}{c}17 \\
(65.38 \%)\end{array}$ & \\
\hline & Linear vessels & $\begin{array}{c}17 \\
(65.38 \%)\end{array}$ & \\
\hline & Hairpin-like vessels & $4(15.3 \%)$ & \\
\hline & Bleeding & $\begin{array}{c}25 \\
(96.1 \%)\end{array}$ & \\
\hline \multicolumn{4}{|l|}{ Palmer wart } \\
\hline & Papillomatous & 17 (63\%) & \\
\hline & $\begin{array}{l}\text { Frogspawn } \\
\text { appearance }\end{array}$ & $\begin{array}{c}12 \\
(44.4 \%)\end{array}$ & \\
\hline & $\begin{array}{l}\text { Yellow gray } \\
\text { structureless }\end{array}$ & $3(11.1 \%)$ & \\
\hline & Dotted vessels & 7 (25.9\%) & \\
\hline & Linear vessels & $3(11.1 \%)$ & \\
\hline & Bleeding & $17(63 \%)$ & \\
\hline \multicolumn{4}{|l|}{ Plantar wart } \\
\hline & Papillomatous & $15(60 \%)$ & \\
\hline & $\begin{array}{l}\text { Frogspawn } \\
\text { appearance }\end{array}$ & II (44\%) & \\
\hline & $\begin{array}{l}\text { Yellow gray } \\
\text { structureless }\end{array}$ & $10(40 \%)$ & \\
\hline & Dotted vessels & $7(28 \%)$ & \\
\hline
\end{tabular}

(Continued) 
Table I (Continued).

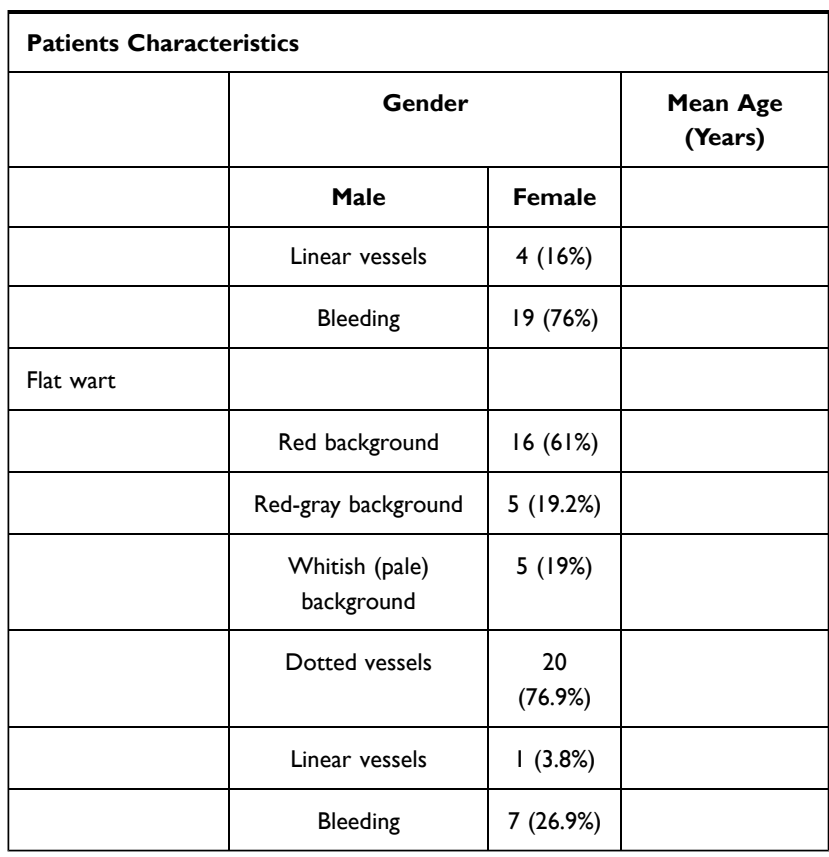

Abbreviation: *sd, standard deviation.

Table 2 Clinical and Dermoscopic Observations in Nonclassical Cutaneous Warts

\begin{tabular}{|c|c|c|c|}
\hline & \multicolumn{3}{|c|}{ Atypical Cutaneous Warts Dermoscopic Features } \\
\hline & Number (\%) & & \\
\hline \multirow{8}{*}{ Common wart } & II (42\%) & & \\
\hline & & Papillomatous & II (100\%) \\
\hline & & Frogspawn appearance & $3(27.27 \%)$ \\
\hline & & Finger-like projections & $2(18.1 \%)$ \\
\hline & & Linear vessels & $6(54.54 \%)$ \\
\hline & & Hairpin-like vessels & I (9\%) \\
\hline & & Dotted vessels & $6(4.54 \%)$ \\
\hline & & Bleeding & $10(90.9 \%)$ \\
\hline \multirow[t]{3}{*}{ Plantar wart } & $2(8 \%)$ & & \\
\hline & & Papillomatous & $\mathrm{I}(50 \%)$ \\
\hline & & Yellow gray structureless & $\mathrm{I}(50 \%)$ \\
\hline \multirow[t]{4}{*}{ Flat wart } & 3 (11.53\%) & & \\
\hline & & Red-gray background & I (33.33\%) \\
\hline & & Whitish (pale) background & $2(66.33 \%)$ \\
\hline & & Dotted vessels & $3(100 \%)$ \\
\hline
\end{tabular}

Cutaneous warts from different parts of the body were involved in the study.

This research was designed to study the dermoscopic features of the following wart types: common warts, palmar warts, plantar warts, flat warts.

Common warts present classically in the clinic as papillomatous hyperkeratotic dome-shaped papule, with the following dermoscopic features: papillomatous, bleeding, linear vessels, hairpin-like vessels, dotted vessels. Palmoplantar warts present as firm papules on palm and sole, with the following dermoscopic features: papillomatous growth, yellow gray structureless, bleeding, linear vessels, dotted vessels. Flat wart clinically appears as slightly elevated brown to skin-colored papules, between 1-5 $\mathrm{mm}$, and dermoscopic features include: red background, red-grey background, whitish (pale) background, accompanied with dotted vessels and bleeding.

We included cutaneous warts that showed the classical clinical and/or dermoscopic characteristics mentioned above. However, some warts may have nonclassical clinical presentation, and, therefore, warts that did not show any of the classical clinical presentation mentioned above were defined as nonclassical warts.

In order to confirm the diagnosis of nonclassical warts, we reviewed the H\&E (hematoxylin and eosin) histopathology slides of nonclassical warts. Any lesions that did not fit the diagnosis criteria were directly excluded.

Analysis of the clinical features and Dermoscopic findings in the aforementioned study was done using SPSS 16.0 for Windows, and the analytical method used was "crosstab", and "Means".

\section{Results}

Of the 104 cases (59 male, 45 female), there were 26 common wart cases (13 male, 13 female), 27 palmar wart cases (17 male, 10 female), 25 plantar wart cases (18 male, 7 female), and 26 flat wart cases (11 male, 15 female) (Table 1).

The mean age for all patients involved in our research was 36 (standard deviation 15.3). Common wart cases had the oldest mean age, with a mean of 51.3 (standard deviation 19.3), while the youngest mean age was that of flat warts, with a mean age of 26.9 (standard deviation 4.2). Moreover, the mean age of palmar and plantar wart cases was 34.1 (standard deviation 11.3) and 29.5 (standard deviation 5.7), respectively (Table 1). 

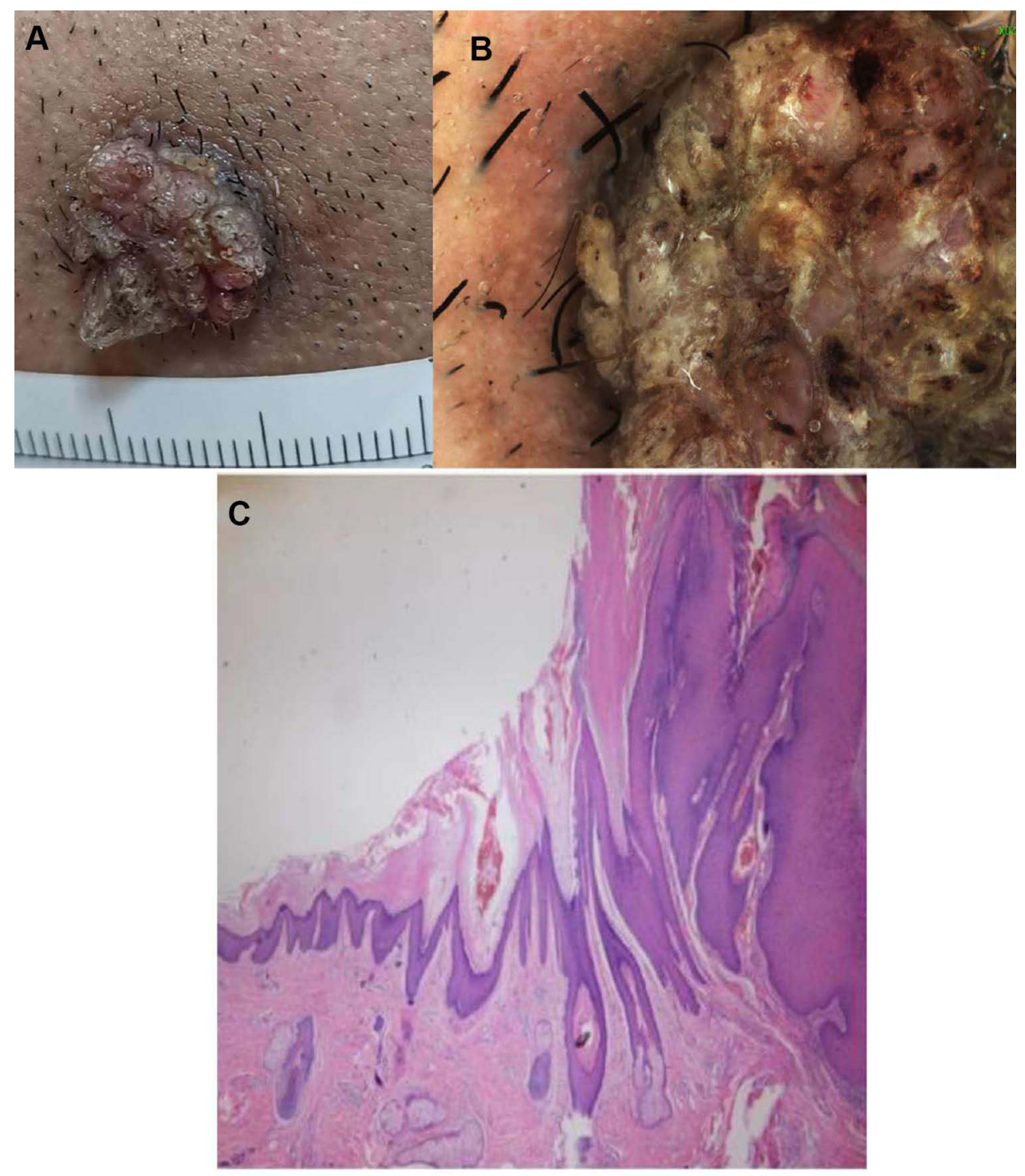

Figure I 4 I years old male with non-classical common wart. Clinical picture (A), dermoscopy (B) and histopathology of the lesion (C).

\section{Common Warts}

Twenty-six of 104 cases were diagnosed as common warts, with $58 \%$ (15 cases) being classical, and $42 \%$ (11 cases) being nonclassical warts (Table 2).

A 41 years old male, with skin papillomatous lesion on his jaw (Figure 1A). The differential diagnosis of this lesion includes squamous cell carcinoma. Dermoscopy showed papillomatous lesion with dotted, linear bleeding spots in the center of the papilla, and dotted, linear blood vessels (Figure 1B). Diagnosis was confirmed on histopathology slide, which showed hyperkeratosis, acanthosis and papillomatous hyperplasia (Figure 1C).

There are distinct patterns of common warts, including finger-like projections and frogspawn appearance.
These are the six different common warts included in our research. They represent the different characteristic patterns found in common warts under the Dermoscopy (Figure 2). Three cases had bleeding spots (Figure 2B, C and F), while (Figure 2A, D and E) had no bleeding spots. Two cases had classical Finger-like projections pattern (Figure 2A and B), while (Figure 2C and D) had fat, short, and unsharp projections. Bleeding spots surrounded by whitish halo known as frogspawn appearance can be seen too (Figure 2C and D). The case in (Figure 2E) shows hairpin-like vessel (black arrow).

\section{Palmar Warts}

All 27 cases of palmar warts showed classical clinical presentation (Table 1). 

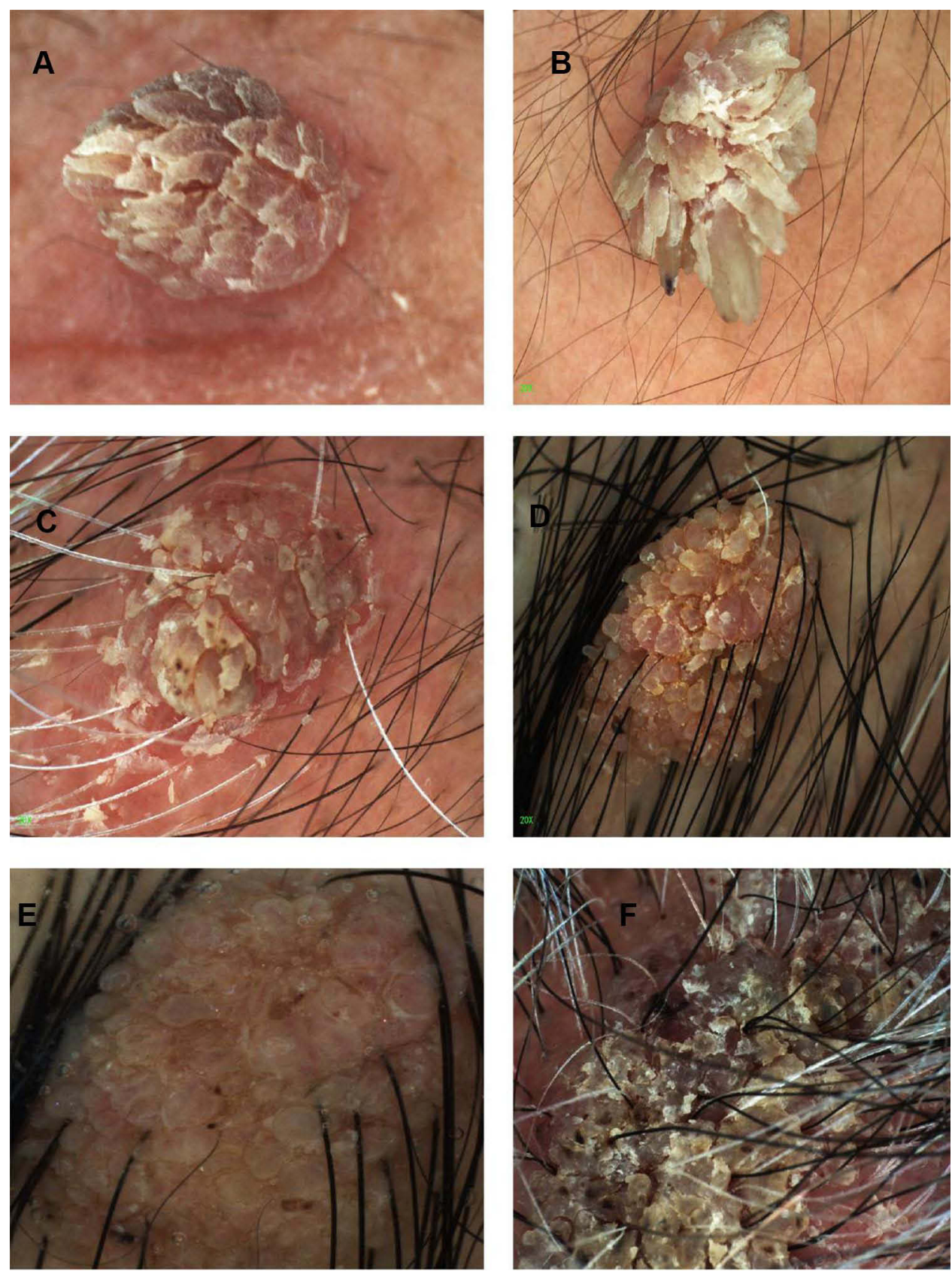

Figure 2 Different patterns of common warts under the dermoscope. (A) finger like projections. (B) Finger like projections with bleeding spots on it. (C) papillomatous lesion with bleeding spots surrounded by whitish known as frogspawn appearance. (D) big number of little fat finger like projections. (E) papillomatous growth accompanied with hairpin-like vessel (black arrow). (F) papillomatous lesion with bleeding spots surrounded by whitish known as frogspawn appearance.

Palmer warts are present commonly in different patterns as shown in (Figure 3). Hemorrhagic points and lines are often surrounded by a whitish halo, known as "Frogspawn pattern" can be seen (Figure 3A-C and F). Papillomatous with a hint of finger-like projections pattern can be seen too (Figure 3D). One case shows dotted vessels on raised pale multiple papillae (Figure 3E), a case that was yellow-grey structureless accompanied by bleeding streaks and spots (Figure 3F).

\section{Plantar Warts}

The 25 plantar wart cases comprised of $92 \%$ presented as clinically classical cases ( 23 cases) and only $8 \%$ presented as nonclassical cases ( 2 cases) (Table 2).

We can see different patterns (Figure 4A-D). Frogspawn pattern was seen in two cases (Figure $4 \mathrm{~A}$ and $\mathrm{B}$ ), while (Figure 4B) had less typical frogspawn appearance. One case had yellowish structureless with bleeding streaks and spots appearance. One case had presented as yellow gray 

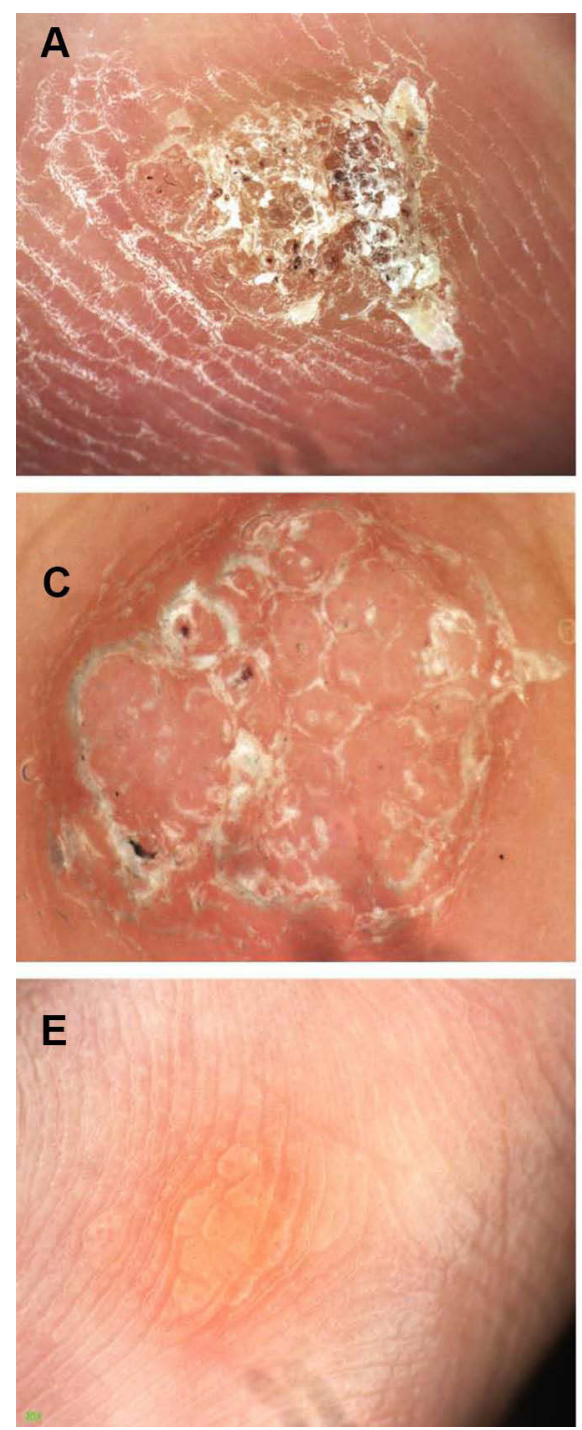
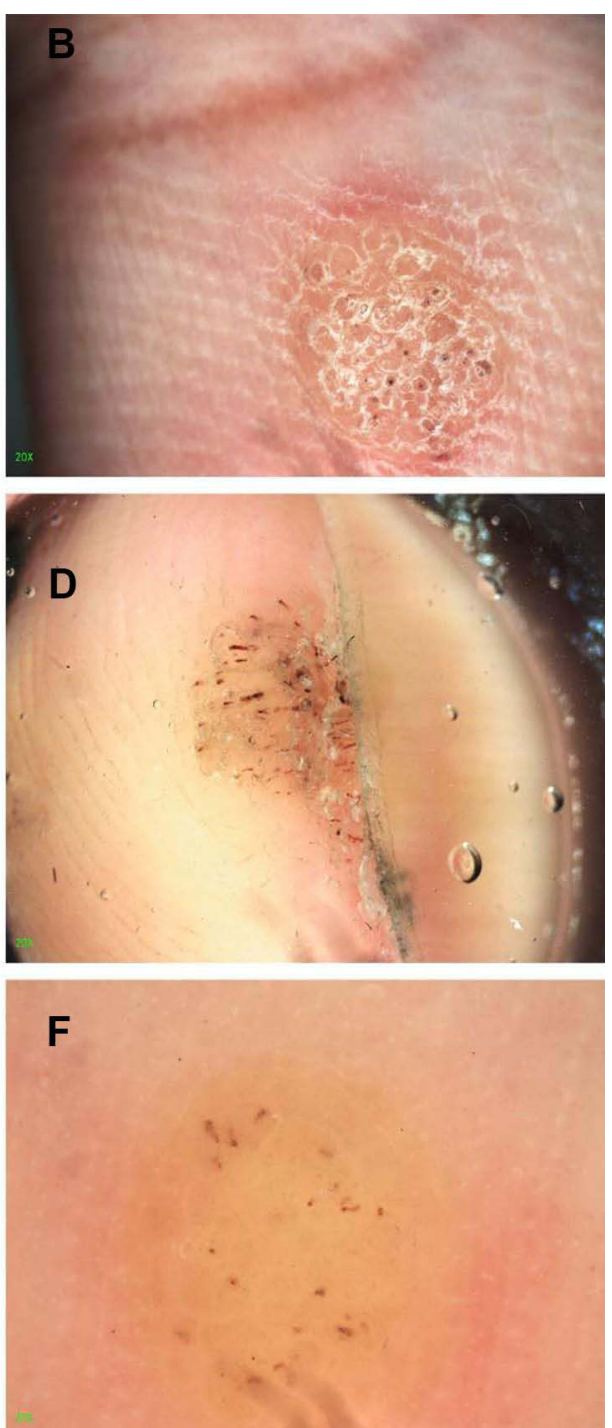

Figure 3 Different patterns of palmer warts under the dermoscope. (A) frogspawn pattern, (B) frogspawn pattern, (C) frogspawn pattern, (D) finger like projections (E) dotted vessels on raised pale multiple papillae $(\mathbf{F})$ yellow-gray structureless.

structureless accompanied with bleeding streaks and spots (Figure 4C). The other case is presented as a papilliform scaly yellowish wart (Figure 4D).

\section{Flat Wart}

Of 26 flat wart cases, $88.5 \%$ (23 cases) showed classical clinical presentation and only $11.5 \%$ (3 cases) were nonclassical (Table 2).

The case shown in (Figure 5A) had two warts, one with dotted vessels on red background (red arrow) pattern and another with dotted vessels on red background with some bleeding spots (blue arrow). Two cases had dotted vessels on a whitish (pale) background shown in (Figure 5B and $\mathrm{C}$ ), according to the patients these warts had appeared only shortly before diagnosis. The case (Figure 5D) presented as dotted vessels on a red-gray background.

\section{Discussion}

Any of the several warts causing HPV strains can give rise to cutaneous warts. The diagnosis of these warts is usually done by examining their clinical features. However, these clinical features do occasionally overlap with those of other lesions, consequently making warts more difficult to diagnose by traditional tools than it should be. For example, cutaneous warts often share certain visual features with other skin lesions such as Dermal Nevus, Seborrheic Keratosis (SK), Acne, and Comedones. Such a dermoscopy would be an invaluable tool in aiding its diagnosis. 

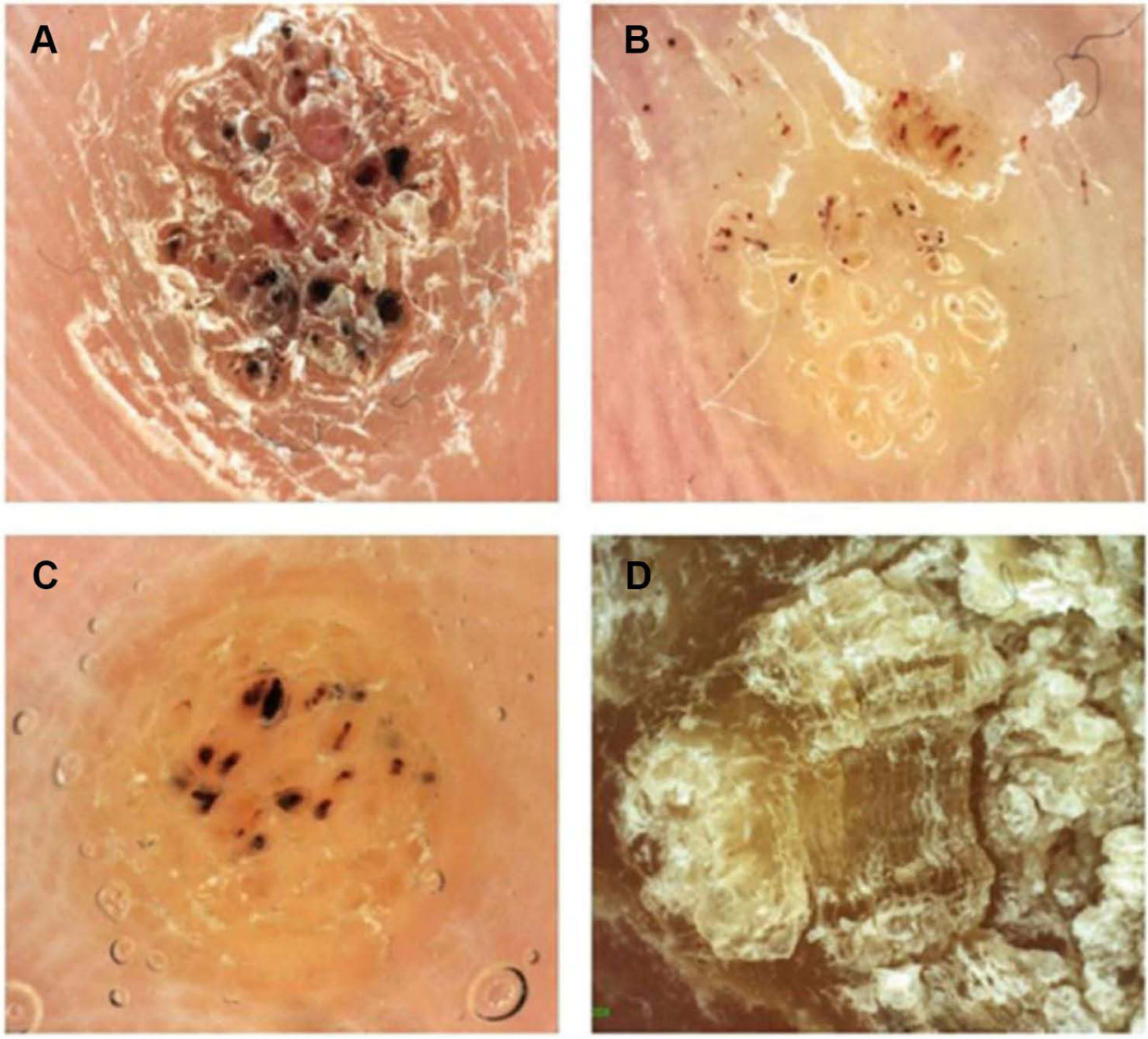

Figure 4 Different patterns of plantar warts under the dermoscope. (A) frogspawn pattern. (B) scaly yellowish structureless with bleeding streaks and spots, (C) yellowgray structureless with bleeding streaks and spots, (D) raised papilliform scaly yellowish wart.

Dermoscopy uses a magnifying lens to make the outermost layer of the skin, the stratum corneum, translucent, thus, allowing us to visualize the structures located in the epidermis and dermal papilla. ${ }^{29}$

The Dermoscopic device used in our study uses polarized light. The polarized light in the modern Dermoscopy devices eliminates the need to make direct contact between the optical lens and the patient's skin, therefore significantly reducing the chance of cross-infection caused by the Dermoscopic device.

In our research, the use of Dermoscopy helped to diagnose clinically non-classical common warts $(42 \%)$, plantar warts $(8 \%)$, and flat warts $(11.5 \%)$ because they facilitate the visualization of typical presentation under Dermoscopy. For this reason, we believe, Dermoscopy can give aid to diagnose those warts, which overlap with other lesions.

Our results were consistent with other literature in many aspects. ${ }^{30,31}$ The common warts cases, as well as palmar and plantar wart cases collected in our study, showed papillomatous growth, bleeding, dotted and linear vessels. These are all very common characteristics and are consistent with other literature. Meanwhile, according to other studies, dermoscopy of flat warts typically reveals regularly distributed, tiny, red dots on a light brown to yellow background. Our study was able to reveal more detailed results, proving that dotted vessels or bleeding could be on red background, red-gray background, or whitish (pale) background, and thus providing more accurate and detailed criteria for the diagnoses of flat warts. ${ }^{31}$ Plantar and palmar warts have been categorized in some studies as "palmoplantar warts", but in our research, we have categorized them into separate groups in order to study their individual clinical and Dermoscopic presentations separately. ${ }^{30}$ The results showed some differences between their clinical and Dermoscopic presentations. The yellow-gray structureless presentation was especially seen as a common presentation in plantar warts but in palmer warts it was an unusual presentation.

Using Dermoscopy, fat warts can be discerned from acne or folliculitis, which usually present as central white to yellowish pore containing pus or comedo within an open hair follicle. ${ }^{31}$ 

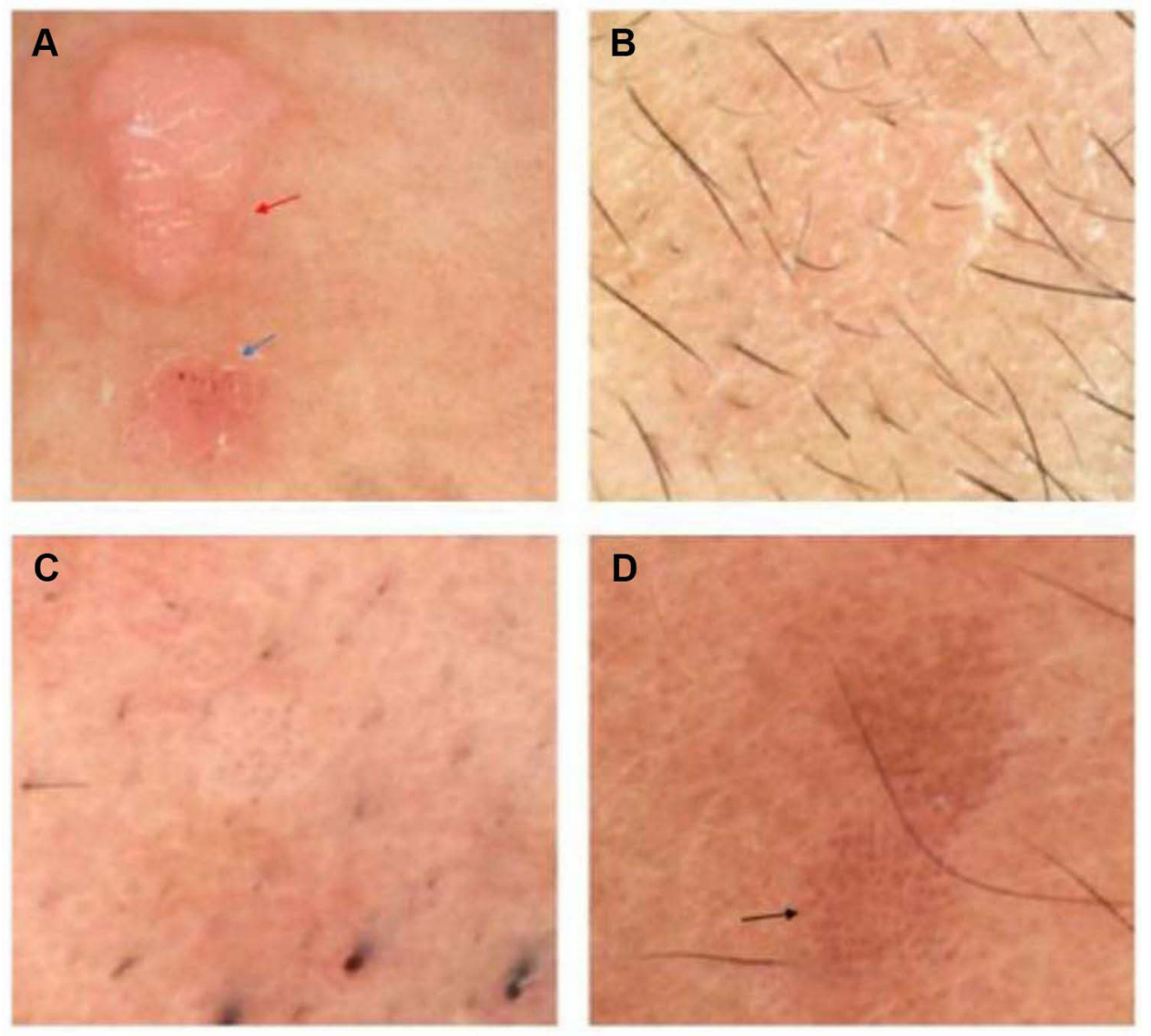

Figure 5 Different patterns of flat warts under the Dermoscope. (A) dotted vessels on red-white back ground (blue arrow) and dotted vessels on red-white back ground with some bleeding spots (red arrow), (B) dotted vessels whitish (pale) background, (C) dotted vessels whitish (pale) background, (D) dotted vessels on a red-gray background (black arrow).

\section{Conclusion}

Different kinds of cutaneous warts share some common features under Dermoscopy, such as papillomatous growth, dotted vessels, linear vessels, bleeding; however, flat warts differ in background colors. Dermoscopy can improve the accuracy of diagnosing different clinically non-classical types of cutaneous warts, in addition to helping in distinguishing them from other similar skin lesions, such as seborrheic keratosis (SK), callus, corns, acne or folliculitis.

\section{Ethics Approval}

The study has been approved by Sir Run Run Shaw Zhejiang University Affiliated Hospital (No.20210708-30). Since this study is a retrospective study, patient consent was not required by the ethics committee of Sir Run Run Shaw Zhejiang University Affiliated Hospital. All human research procedures were followed in accordance with the ethical standards of the committee responsible for human experimentation (institutional and national), and with the Helsinki Declaration of 1975, as revised in 2013.

\section{Acknowledgments}

No funding was required for this research. This research was conducted in the absence of any commercial or financial relationship that could be construed as a potential conflict of interest. Dr. Mus'ab Al Rudaisat and Prof. Hao Cheng designed the study, wrote and revised the manuscript, and analyzed the data, while data collection was conducted by Dr.Mus'ab Al Rudaisat.

\section{Disclosure}

The authors report no conflicts of interest in this work.

\section{References}

1. Kirnbauer EJAR. Warts in Fitzpatrick's dermatology in general medicine; 2008.

2. Jablonska S, Majewski S, Obalek S, Orth G. Cutaneous warts. Clin Dermatol. 1997;15(3):309-319. PubMed PMID: 9255438. doi:10.1016/s0738-081x(96)00170-8

3. Santos-Lopez G, Marquez-Dominguez L, Reyes-Leyva J, VallejoRuiz V. [General aspects of structure, classification and replication of human papillomavirus]. Rev Med Inst Mex Seguro Soc. 2015;53(Suppl 2):S166-S171. PubMed PMID: 26462512. Spanish. 
4. Sterling JC, Gibbs S, Haque Hussain SS, Mohd Mustapa MF, HandfieldJones SE. British Association of Dermatologists' guidelines for the management of cutaneous warts 2014. Br J Dermatol. 2014;171(4):696-712. PubMed PMID: 25273231. doi:10.1111/bjd.13310

5. Chen SL, Tsao YP, Lee JW, Sheu WC, Liu YT. Characterization and analysis of human papillomaviruses of skin warts. Arch Dermatol Res. 1993;285(8):460-465. PubMed PMID: 8274034. doi:10.1007/ BF00376818

6. Bruggink SC, de Koning MN, Gussekloo J, et al. Cutaneous wart-associated HPV types: prevalence and relation with patient characteristics. J Clin Virol. 2012;55(3):250-255. PubMed PMID 22884670. doi:10.1016/j.jcv.2012.07.014

7. Fee JA, McGrady FP, Rosendahl C, Hart ND. Dermoscopy use in primary care: a scoping review. Dermatol Pract Concept. 2019;9 (2):98-104. PubMed PMID: 31106011. doi:10.5826/dpc.0902a04

8. Wolner ZJ, Yelamos O, Liopyris K, Rogers T, Marchetti MA, Marghoob AA. Enhancing skin cancer diagnosis with dermoscopy. Dermatol Clin. 2017;35(4):417-437. PubMed PMID: 28886798; PubMed Central PMCID: PMCPMC5659633. doi:10.1016/j. det.2017.06.003

9. Cook LC, Hanna C, Foulke GT, Seiverling EV. Dermoscopy in the diagnosis of inflammatory dermatoses: systematic review findings reported for psoriasis, lupus, and lichen planus. J Clin Aesthet Dermatol. 2018;11(4):41-42. PubMed PMID: 29657671; PubMed Central PMCID: PMCPMC5891086.

10. Bakos RM, Blumetti TP, Roldan-Marin R, Salerni G. Noninvasive imaging tools in the diagnosis and treatment of skin cancers. Am J Clin Dermatol. 2018;19(Suppl1):3-14. PubMed PMID: 30374899; PubMed Central PMCID: PMCPMC6244601. doi:10.1007/s40257-018-0367-4

11. Shen X, Yu RX, Shen CB, et al. Dermoscopy in China: current status and future prospective. Chin Med J. 2019;132(17):2096-2104. PubMed PMID: 31433330; PubMed Central PMCID: PMCPMC6793796. doi:10.1097/CM9.0000000000000396

12. Kittler H, Pehamberger H, Wolff K, Binder M. Diagnostic accuracy of dermoscopy. Lancet Oncol. 2002;3(3):159-165. PubMed PMID: 11902502. doi:10.1016/s1470-2045(02)00679-4

13. Rosendahl C, Cameron A, McColl I, Wilkinson D. Dermatoscopy in routine practice - 'chaos and clues'. Aust Fam Physician. 2012;41 (7):482-487. PubMed PMID: 22762066.

14. Jones OT, Jurascheck LC, Utukuri M, Pannebakker MM, Emery J, Walter FM. Dermoscopy use in UK primary care: a survey of GPs with a special interest in dermatology. $J$ Eur Acad Dermatol Venereol. 2019;33(9):1706-1712. PubMed PMID: 30977937; PubMed Central PMCID: PMCPMC6767170. doi:10.1111/jdv.15614

15. Binder M, Schwarz M, Winkler A, et al. Epiluminescence microscopy. A useful tool for the diagnosis of pigmented skin lesions for formally trained dermatologists. Arch Dermatol. 1995;131(3):286-291. PubMed PMID: 7887657. doi:10.1001/archderm.131.3.286

16. Binder M, Puespoeck-Schwarz M, Steiner A, et al. Epiluminescence microscopy of small pigmented skin lesions: short-term formal training improves the diagnostic performance of dermatologists. $\mathrm{J} \mathrm{Am}$ Acad Dermatol. 1997;36(2 Pt 1):197-202. PubMed PMID: 9039168. doi:10.1016/s0190-9622(97)70280-9

17. Vestergaard ME, Macaskill P, Holt PE, Menzies SW. Dermoscopy compared with naked eye examination for the diagnosis of primary melanoma: a meta-analysis of studies performed in a clinical setting. Br J Dermatol. 2008;159(3):669-676. PubMed PMID: 18616769. doi:10.1111/j.1365-2133.2008.08713.x
18. Blum A. Some thoughts on the 'three-point checklist of dermoscopy' by Soyer et al. Dermatology. 2004;209(2):167;author reply -8 . PubMed PMID: 15316179. doi:10.1159/000079609

19. Luttrell MJ, McClenahan P, Hofmann-Wellenhof R, Fink-Puches R, Soyer HP. Laypersons' sensitivity for melanoma identification is higher with dermoscopy images than clinical photographs. $\mathrm{Br}$ $J$ Dermatol. 2012;167(5):1037-1041. PubMed PMID: 22762457. doi:10.1111/j.1365-2133.2012.11130.x

20. Bafounta ML, Beauchet A, Aegerter P, Saiag P. Is dermoscopy (epiluminescence microscopy) useful for the diagnosis of melanoma? Results of a meta-analysis using techniques adapted to the evaluation of diagnostic tests. Arch Dermatol. 2001;137(10):1343-1350. PubMed PMID: 11594860. doi:10.1001/archderm.137.10.1343

21. Menzies SW, Emery J, Staples M, et al. Impact of dermoscopy and short-term sequential digital dermoscopy imaging for the management of pigmented lesions in primary care: a sequential intervention trial. $\mathrm{Br} J$ Dermatol. 2009;161(6):1270-1277. PubMed PMID: 19747359. doi:10.1111/j.1365-2133.2009.09374.x

22. Westerhoff K, McCarthy WH, Menzies SW. Increase in the sensitivity for melanoma diagnosis by primary care physicians using skin surface microscopy. $\mathrm{Br} \quad J$ Dermatol. 2000;143(5):1016-1020. PubMed PMID: 11069512. doi:10.1046/j.1365-2133.2000.03836.x

23. Argenziano G, Puig S, Zalaudek I, et al. Dermoscopy improves accuracy of primary care physicians to triage lesions suggestive of skin cancer. J Clin Oncol. 2006;24(12):1877-1882. PubMed PMID: 16622262. doi:10.1200/JCO.2005.05.0864

24. Dolianitis C, Kelly J, Wolfe R, Simpson P. Comparative performance of 4 dermoscopic algorithms by nonexperts for the diagnosis of melanocytic lesions. Arch Dermatol. 2005;141(8):1008-1014. PubMed PMID: 16103330. doi:10.1001/archderm.141.8.1008

25. Pagnanelli G, Soyer HP, Argenziano G, et al. Diagnosis of pigmented skin lesions by dermoscopy: web-based training improves diagnostic performance of non-experts. Br J Dermatol. 2003;148(4):698-702. PubMed PMID: 12752126. doi:10.1046/j.1365-2133.2003.05168.x

26. Rogers T, Marino ML, Dusza SW, et al. A clinical aid for detecting skin cancer: the triage amalgamated dermoscopic algorithm (TADA). $J$ Am Board Fam Med. 2016;29(6):694-701. PubMed PMID: 28076252; PubMed Central PMCID: PMCPMC5536949. doi:10.3122/jabfm.2016.06.160079

27. Secker LJ, Buis PA, Bergman W, Kukutsch NA. Effect of a dermoscopy training course on the accuracy of primary care physicians in diagnosing pigmented lesions. Acta Derm Venereol. 2017;97(2):263-265. PubMed PMID: 27572816. doi:10.2340/00015555-2526

28. National Institute for Clinical Excellence. 14 Melanoma assessment \& management. UK: National Institute for Clinical Excellence; 2015.

29. Argenziano G, Cerroni L, Zalaudek I, et al. Accuracy in melanoma detection: a 10-year multicenter survey. J Am Acad Dermatol. 2012;67 (1):54-59. PubMed PMID: 21982636. doi:10.1016/j.jaad.2011.07.019

30. Lee DY, Park JH, Lee JH, Yang JM, Lee ES. The use of dermoscopy for the diagnosis of plantar wart. J Eur Acad Dermatol Venereol. 2009;23(6):726-727. PubMed PMID: 19309426. doi:10.1111/j.14683083.2009.03184.x

31. Penso-Assathiany D, Gheit T, Pretet JL, et al. Presence and persistence of human papillomavirus types 1, 2, 3, 4, 27, and 57 on dermoscope before and after examination of plantar warts and after cleaning. J Am Acad Dermatol. 2013;68(1):185-186. PubMed PMID: 23244381. doi:10.1016/j.jaad.2012.07.011 


\section{Publish your work in this journal}

The International Journal of General Medicine is an international, peer-reviewed open-access journal that focuses on general and internal medicine, pathogenesis, epidemiology, diagnosis, monitoring and treatment protocols. The journal is characterized by the rapid reporting of reviews, original research and clinical studies across all disease areas. The manuscript management system is completely online and includes a very quick and fair peer-review system, which is all easy to use. Visit http://www.dovepress.com testimonials.php to read real quotes from published authors.

Submit your manuscript here: https://www.dovepress.com/international-journal-of-general-medicine-journal 